\title{
The Puzzle of Humility and Disparity
}

\author{
Dennis Whitcomb, Heather Battaly, Jason Baehr, and Daniel Howard-Snyder \\ Final Draft (aside from copyediting)
}

This is a preprint. The published version appears in Routledge Handbook of the Philosophy of Humility, eds. Alfano, Lynch, and Tanesini, 2021.

True story: when the female members of a colleague's research lab learned of his plans to study humility, they remarked: "Humility is exactly what you need more of, if you're a white male!" Subtext: humility is uncalled for when you're oppressed. Frederick Douglass observed something similar with respect to the horrific source of oppression that was American slavery:

With a book in my hand so redolent of the principles of liberty, and with a perception of my own human nature and of the facts of my past and present experience, I was equal to a contest with the religious advocates of slavery, whether white or black; for blindness in this matter was not confined to the white people. I have met, at the south, many good, religious colored people who were under the delusion that God required them to submit to slavery and to wear their chains with meekness and humility. I could entertain no such nonsense as this.... (Douglass 1892, 104-105)

Humility seems the last thing the enslaved need. More generally, and to put it mildly, humility seems to be an inappropriate response for the oppressed toward their oppressors. It seems inappropriate elsewhere too. If you find yourself accosted by a neo-Nazi who advocates reinstating the Final Solution, humility seems like the wrong response, just as it does when you're evangelized by a flat-earther. In sum, humility seems inappropriate as a response in a variety of contexts. But how can this be? If humility is a virtue, and if to act virtuously is to act well, how can it ever be inappropriate to act humbly?

To sharpen this puzzle, we'll use the phrase "contexts of disparity" to capture interactions in which people differ dramatically along a normative dimension, where some are in the right and others are in the wrong. If you're an oppressed person interacting with your oppressor, or if you're buttonholed by neo-Nazis or flat-earthers, you are in a context of disparity. In each case, you differ dramatically from others along a normative dimension-social power in the case of oppression, moral credentials in the case of neo-Nazism, and epistemic credentials in the case of flat-earthism-and you are in the right and they are in the wrong. To be sure, there are important differences across different "contexts of disparity". For instance, the oppressed are harmed systematically (and often horrifically) whereas those who face wielders of heinous or ridiculous views may be harmed in one-off ways or even not harmed at all. In terms of harm, then, some contexts of disparity are utterly unimportant compared to others. Nonetheless, the concept of "contexts of disparity" captures something important these interactions all share: due to a dramatic normative difference, humility seems to misadvise those who are in the right about how to respond to those who are in the wrong.

Again we wonder: how can this be? Is it because humility is not a virtue, as Hume (1751/1975) argued? Or is it instead that genuine virtues sometimes misadvise us? Or, if they never misadvise us, are they nonetheless sometimes unimportant or irrelevant or silent? Or might it so happen that humility gives us correct advice after all, even when we are in the right in contexts of disparity? This thicket of questions entangles us; what follows is our attempt to work through it.

\section{First lesson: the importance of humility is limited}


Contexts of disparity reveal that the importance of humility is limited in several ways. First, it is limited because it is limited for in-the-right parties in contexts of disparity relative to in-the-wrong parties in those contexts. The in-the-wrong parties in these contexts should be much more concerned with humility than the in-the-right parties. Theirs are the thinking, sentiments, and behavior that blatantly manifest humility's lack; theirs is the primary responsibility to increase humility's exercise. ${ }^{1}$ Second, the importance of humility is limited because it is limited for in-the-right parties in contexts of disparity relative to other virtues for those parties in those contexts. More than humility, those parties should draw on self-respect, self-trust, courage, and perseverance. ${ }^{2}$ Perhaps most centrally, they should draw on pride: an attentiveness to and ownership of their strengths (Whitcomb et al 2017, 528-532). Third, virtues in general, humility included, are plausibly at least sometimes less important than certain other things when it comes to contexts of disparity - less important in perhaps several senses, including (at least) the sense that our ameliorative efforts should focus on those other things before focusing on the cultivation of virtues. For instance, social structures such as laws against slavery, or integrated educational systems, or social media content feed algorithms reducing the spread of false information, are plausibly at least sometimes more important when it comes to contexts of disparity than are any virtues, humility included. Our efforts should, at least sometimes, focus on improving such social structures before they focus on improving peoples' statuses as virtuous.

There is a fourth way, too, in which contexts of disparity reveal limits of the importance of humility. In order to explain this one, we'll need to first explain our theory of the nature of humility. In Whitcomb et al (2017), we argued that the trait of intellectual humility consists in being both attentive to and owning one's intellectual limitations such as cognitive mistakes, gaps in knowledge, deficits in cognitive skills, intellectual character flaws, and so forth. On our view, the trait of humility per se consists in being both attentive to and owning a much broader range of one's limitations such as moral mistakes (e.g., breaking a promise), affective shortcomings (e.g., lacking a sense of humor), deficits in general skills (e.g., being a terrible cook or an awful driver), flaws in moral character (e.g., being cowardly or rash), and so on.

For the humble to be attentive to their limitations is for them to be disposed in such a way that their limitations come to mind routinely, in contrast with being oblivious to them. So a person who is completely inattentive to their limitations cannot be humble. However, someone can be attentive to their limitations while also being flagrantly complacent about them, attempting systematically to conceal them from others, or responding defensively whenever they are brought to light. They would not be humble either. Accordingly, the humble also own their limitations.

For the humble to own their limitations is for them to be so disposed that, when their limitations come to mind, they respond in such a way that excludes flagrant complacence, systematic concealment, chronic defensiveness, and the like. More generally, owning one's limitations characteristically involves dispositions to (i) believe and accept that one has them, (ii) admit and acknowledge them, (iii) care about them and take them seriously, and (iv) feel regret or dismay about them. Owning one's limitations tracks familiar ways of thinking and speaking, as when we tell a friend it is high time for them to "own their shit", or when we encourage a loved-one to "own their addiction", or when a losing team "owns its poor play".

That is our theory of the trait of humility, roughly. If it is correct, then (among other things) the humble will be more likely than the non-humble to admit their limitations to others, defer to others, seek help from others, and have a low concern for status, and they will be less likely to set unattainable goals and disrespect others. (See Whitcomb et al 2017, 13-26).

Note that someone can possess the trait of humility while lacking the virtue of humility, for at least two reasons.

First, someone might be disposed to attend to and own their limitations but at the wrong time, toward the wrong people, or in the wrong way. If this disposition is entrenched in their psychology, they 
might be humble; however, their humility would not be a virtue since they might be excessively humble or foolishly so. For the trait of humility to be a virtue in someone, they must possess phronesis (or sometime similar), i.e. good practical judgment, whereby they know when, toward whom, and how to attend to and own their limitations.

Gary Watson makes a similar point about benevolence: "the word 'benevolence' names both a general concern for others (which may be excessive, and lead to bad action) and the qualified and informed concern that constitutes the virtue" $(1984,68)$. Watson's point applies widely. Just as an excess of the trait of benevolence can cause one to donate without considering an organization's merit, an excess of the trait of open-mindedness can cause one to engage perspectives that aren't helpful in reaching the truth (Baehr 2011), an excess of the trait of intellectual perseverance can cause one to stick with projects that are ill-fated (Battaly 2017), and-pertinently-an excess of the trait of humility can cause one to defer without considering the epistemic or moral credentials of the view or person one is deferring to. More generally, an excess of the trait of humility can cause one to be overly attentive to, or to over-own, one's limitations. If you constantly attend to your limitations, or you routinely over-emphasize them, overattribute negative outcomes to them, or care too much about them, or they regularly overwhelm you, then you lack the virtue of humility, even though you possess the trait. You are humble to a fault. We call this excess servility, which tends to be vicious. On our view, then, the virtue of humility lies in a mean between the vice of servility and a corresponding vice of arrogance, which involves deficient attentiveness to, and under-owning of, one's limitations.

Second, someone disposed to attend to and own their limitations at the right time, toward the right people, and in the right way, might nevertheless be disposed to do so for the wrong reason, in which case they will have the trait but not the virtue of humility. For example, a power-hungry faculty member who aims to be elected department chair, but whose department values humility, might set out to cultivate a settled disposition to attend to and own their limitations at the right time, in the right way, and so on. Even if they succeed, they do not possess the virtue of humility since the motives that underlie their humility do not make them better as a person (Baehr 2011, ch. 6; Battaly 2015, ch. 3).

On our view, the virtue of humility is a disposition to appropriately attend to and own one's limitations. We can't emphasize strongly enough that the form this takes can vary significantly across situations. For instance, in some cases it may call for one to explicitly acknowledge one's limitations to someone else, e.g., when you've callously offended them, while in other cases it might call for one simply to admit the limitation to oneself, e.g., when you realize that you're not as gifted as you thought. Another example: compare owning one's struggle with abstract reasoning with owning one's tendency to irresponsibly gossip. If you can't do anything about the first but you can do something about the second, then appropriately owning the first might involve little more than accepting it while appropriately owning the second might involve resolving to get rid of it.

Applying these views to contexts of disparity, we can delineate a fourth way in which the importance of humility is limited, to wit: if it is the trait we are talking about, then in contexts of disparity humility does indeed sometimes misadvise those who are in the right. Douglass was right, about the trait that is humility. For the trait can be excessive, thus amounting to servility. In such cases, the trait can advise in-the-right parties to engage in such inappropriate acts as deferring to a neo-Nazis or flat-earthers or (in the slavery case) refraining from resisting one's owners. A trait that sometimes yields inappropriate actions such as these is thereby of limited importance.

To recapitulate: humility's importance is limited because it is limited for those in the right in contexts of disparity in at least four ways. Limitations-owning itself has its limits.

\section{Second lesson: Humility is important, even for those in the right in contexts of disparity}


We've argued that the importance of humility is limited. Some readers might conclude, with apologies to Larry David and the Templeton Foundation, that we should curb our enthusiasm about it. But that would be a mistake. For, despite its limits, humility - that is, the virtue of humility - does play several important roles, even for those who are in the right in contexts of disparity. Or so we'll argue.

It is with some unease that we will share these arguments. W.E.B. Du Bois observes that slaveholders encouraged slaves to be humble: "The long system of repression and degradation of the Negro tended to emphasize the elements of his character which made him a valuable chattel: courtesy became humility, moral strength degenerated into submission..." (1903/1994, 121). Following suit, Nancy Snow observes that slaveholders encouraged "certain traits or 'virtues"" in slaves, including "docility...shame, gratitude, loyalty...[and] humility," since the humble and docile were easier to control $(2004,60)$. These passages make us worry that our arguments might generate grist for the mill of those who would abuse the language of humility to keep oppressed people down. But we'll share those arguments nonetheless, for two reasons. First, while there are no doubt cases where theorizing should remain unshared due to its potential for abuse, the downside risk must be weighed against upside potential. In the current case the upside potential is non-trivial, because (we'll argue) a proper understanding of the virtue of humility reveals that it is not demeaning or submissive or degrading but instead enables informed, forceful, and courageous moral and intellectual action. Second, although there is a heartening current trend in the opposite direction, moral theorizing among academic philosophers has long failed to pay sufficient heed to conditions of oppression. The current trend in the opposite direction ought to continue and expand. We offer our arguments with the goal of contributing to that continuation and expansion. Without further ado then, we'll argue that there are at least five important roles the virtue of humility can play, even for those in the right in contexts of disparity.

2.1. Ambition. The virtue of humility helps us balance our ambition, both by tempering it and by bolstering it. As for tempering, the virtue of humility sometimes keeps us from biting off more than we can chew (Helgevold 2013, 127; Whitcomb et al 2017, 522). That's because, when we own our limitations, we are more apt than we otherwise would be to temper our ambitions and set achievable goals. This does not mean that our goals aren't difficult; rather, it means that they aren't too difficult given our limitations. For instance, suppose a flat-earther confronts you. Thinking too highly of your powers of persuasion, you might endeavor to convince them on the spot that they are wrong, to produce a disquisition so incisive that they see the light and immediately recant. The virtuously humble are more apt to acknowledge that this goal is beyond reach. In the service of other virtues, like charity or curiosity, the virtue of humility can help one set appropriately difficult goals with respect to the flat-earther. One such goal might be to understand what motivates this person's belief. And another, if one is especially charitable, might be to formulate and enact a several-step plan in light of that motivation such that, once those steps are implemented, the flat-earther may begin rethinking his view. In this way, the virtue of humility can play a supporting role in relation to the virtues of charity or curiosity-it can help us set goals that are appropriately difficult instead of goals that are too difficult.

The black musician Daryl Davis (1958-) may be a case in point. He has gradually convinced several KKK members to leave the Klan. In a documentary film about his efforts, he compares changing the mind of a Klan member to losing weight. He says: "Y'all see this fine figure right here [indicating his ample midsection]? I didn't put this on overnight. I want to lose it. I'm not going to lose it by tomorrow. But, if I work on it over time, it will shrink down. When you are engrained in this stuff [white supremacy], you are not going to shut it off overnight" (Accidental Courtesy 2016, 13:58). Davis owns his inability to immediately change the minds of Klan members; so he tempers his ambitions, thereby removing obstacles to drawing on charity, inviting Klan members to conversations and meals, with some success. 
The virtue of humility also helps keep us from biting off less than we should. Imagine someone who over-owns his limitations by paying too much heed to them, attributing too many shortcomings to them, and so on. Such a person might refrain from resisting racism at all, in any way, because he (wrongly) judges that he is poorly-equipped for the task. Or imagine a person who incorrectly thinks his powers of interpersonal pedagogy are so limited that he can't knock even the tiniest chip away from the worldview of a flat-earther. Such a person, taking himself to be unable, might refrain from trying to make any progress with the flat-earther. In cases such as these, people refrain from setting appropriately ambitious goals not because their goals are too ambitious but instead because their goals aren't ambitious enough. Their failures to set appropriately ambitious goals manifest the vice of servility, of over-owning one's limitations. The virtue of humility corrects for such failures by bolstering our ambitions. It does so by keeping us from over-owning our limitations, keeping us balanced in the mean of appropriate owning, between the extremes of excessive and deficient owning.

2.2. Belief. The virtue of humility also tempers and bolsters belief. With respect to tempering, it helps us to refrain from forming beliefs that outstrip our evidence, by making us aware of ways in which our evidence supports only a limited range of claims to a limited extent (Whitcomb et al. 2017, 525). For example, humility might make us aware that our evidence does not support the conclusion that in-thewrong parties are irredeemable monsters or hopeless dolts and, having owned that fact, enable us to overcome the temptation to draw it. As a result, we are freed to draw on intellectual virtues like fairmindedness and moral virtues like justice to help us follow the often-difficult advice of Martin Luther King $(1963,45)$ :

[W]e must recognize that the evil deed of the enemy-neighbor, the thing that hurts, never quite expresses all that he is. An element of goodness may be found even in our worst enemy.... When we look beneath the surface, beneath the impulsive deed, we see within our enemy-neighbor a measure of goodness and know that the viciousness and evilness of his acts are not quite representative of all that he is.

That is, humility can help us recognize that in-the-wrong parties are not monsters but rather humans, who may even occasionally, or in some domains of their lives, do things that are morally or intellectually appropriate. Humility can help us recognize that our interlocutors may not possess moral and intellectual vices across all domains, though they may possess those vices and/or perform vice-characteristic actions in some domains.

Interestingly, the virtue of humility can also help oppressed people resist internalizing the perspective of the oppressor. Since humility tends to keep us from forming beliefs that outstrip our evidence, it might help prevent oppressed people from believing they are inferior or worthless. Just as humility can keep us from jumping to the conclusion that an in-the-wrong party is a monster or a dolt, it can keep oppressed people from jumping to the conclusion that they are inferior or worthless, or at least slow the process of internalization.

The virtue of humility doesn't only temper belief by keeping us from under-owning our limitations; it also bolsters belief by keeping us from over-owning our limitations. Over-owning the limitations of your evidence or reasoning powers, you might refrain from believing that Klan members or neo-Nazis or flatearthers are making serious mistakes; for you might think your evidence and reasoning abilities do not quite justify such beliefs. In such a scenario you would manifest the vice of servility. The proper corrective would be the virtue of humility, the virtue through which you own your limitations appropriately instead of excessively or deficiently.

2.3. Emotion. In the passage quoted above, MLK also claims that "there is some good in the worst of us and some evil in the best of us. When we discover this, we are less prone to hate our enemies" $(1963,45)$. This suggests that the virtue of humility can also help us temper our emotions. It helps, first, 
by alerting us to our tendencies toward excess, e.g., to respond to flat-earthers with disgust or rage, and second, by enabling us to own them and so to respond appropriately, e.g., by taking steps to retrain our emotions (Coplan 2010). Sometimes, in contexts of disparity, anger is called for but white-hot rage is not; sometimes antipathy is called for but unrelenting hatred is not; sometimes dislike is called for but revulsion is not. By alerting us to our tendencies to excessive emotion and enabling us to own them, humility allows us to draw on a range of other virtues in contexts of disparity, including what Aristotle calls 'good-temper', which involves avoiding excessive anger, i.e. being "angry at the right things and with the right people, and...as we ought, when we ought, and as long as we ought" (NE.1125b32-33, ungendered).

We can't emphasize strongly enough that, in contexts of disparity, the virtue of humility helps temper our emotions when such tempering is called for. We claim, not that the virtue of humility always calls for such tempering, but rather that it sometimes does. So then: when, exactly, does the virtue of humility call for the tempering of emotion in contexts of disparity? This is a difficult question to which we have no complete answer. But we can say this much.

Tempered emotion is called for in one-off interactions with flat-earthers, when one has a tendency to respond with loathing and rage rather than dismay and frustration. Perhaps, tempering is even called for in some one-off interactions with neo-Nazis and Klan members, though these cases will be more complex since the normative dimension will have shifted from epistemic ridiculousness to massive moral heinousness and one's social identity might justify a less-than-tempered response. Here, intense rage and loathing may be appropriate, even if hardened, merciless, and terrifying rage or dehumanizing hatred would be excessive.

The really difficult case, though, is horrific oppression. Might tempered emotion be called for on the part of the oppressed in the face of their oppressors? Tessman argues that an unsurpassable level of unrelenting rage and hatred is an appropriate affective response to proponents of systematic racism, in which case tempering is not called for $(2005,115-117,124)$. In the same vein, bell hooks writes: "Many African Americans feel uncontrollable rage when we encounter white supremacist aggression. That rage is not pathological. It is an appropriate response to injustice" $(1995,26)$. In contrast, MLK, Jesus, Ghandi and others (e.g. Silvermint 2017) advise against hatred and the sort of hardened resolve against one's oppressors that leads to dehumanization. We do not feel well-positioned to resolve this dispute. ${ }^{3}$ But we do think that even if tempering anger and hatred has no place in contexts of horrific oppression, it will still be relevant in other contexts of disparity.

Crucially, the virtue of humility not only tempers but also bolsters - with emotion as well as ambition and belief. Just as it brings us to appropriately own and thus manage the limitations which are our tendencies to excess emotion, it also brings us to appropriately own and thus manage the limitations which are our tendencies to deficient emotion. When what is called for is more anger or fear or disgust or dismay, so that we are limited in not having enough of these things, the virtue of humility brings us attend to and appropriately own, and thus manage, these emotional limitations. For instance, suppose that you are no longer angry with Klan members, having been numbed to them over the years. The virtue of humility would bring you to attend to and own this emotional deficiency. It would thereby set the stage for proper management. Frequently this management would consist in retraining your emotions to make them stronger, though in some cases it might consist in coming to peace with them while continuing to recognize them as deficient. Similar points apply in other cases of deficient emotion such as insufficient dismay with flat-earthers.

2.4. Seeking and accepting assistance. In contexts of disparity, the virtue of humility can help us seek and accept assistance when (and only when) we need it (Whitcomb et al 2017, 524). Moreover, it can help us appropriately manage our affective responses to receiving or avoiding this assistance.

For one example, the virtue of humility can help people seek and accept assistance in their efforts to survive or resist oppression. It can help them, first, to recognize the limitations of their ability to 
respond to oppression alone and, second, to own the need for outside assistance, e.g., by mitigating the effects of debilitating feelings of guilt about needing and receiving assistance. ${ }^{4}$ In this manner, the virtue of humility might pave the way for other virtues involved in surviving or resisting oppression, e.g., courage, perseverance, and justice. ${ }^{5}$

For another example, imagine being challenged by a flat-earther to give them, on the spot, your evidence to think that the earth is round. You haven't thought about the matter since high school, and you don't remember much about it. Humility can help you to own your failure to remember, keep you from trying to fake a response, check your rising embarrassment and/or frustration with yourself. With these impediments nullified by humility, other virtues can kick in if the matter is important enough to you to pursue, e.g. curiosity, fairmindedness, and thoroughness as you throw yourself into the requisite research. In these ways, the virtue of humility helps us seek and accept assistance when we should do those things. It does this by keeping us from under-owning our limitations.

Are there also cases in which one is too inclined to seek and accept assistance or too emotionally at ease with doing so? And, if there are, can the virtue of humility help in these cases? Analyses of the virtue of autonomy will tell us whether and when one can be excessively inclined to seek and accept assistance, and whether and when it is appropriate to exercise one's own agency. ${ }^{6}$ When the virtue of autonomy calls for exercising one's own agency, the virtue of humility can play a supporting role by keeping us from over-owning our limitations. People with the virtue of humility don't pay their limitations excessive heed, and so won't (at least not via such heed) refrain from exercising their own agency in cases where that is appropriate.

2.5. Engaging the Other. Believing that in-the-wrong parties are monsters, or hating them with a resolve that hardens us against their humanity, can lead us to disengage with them: to leave them to their own devices away from our clean hands. While disengagement is surely sometimes called for, surely other times it is not. Virtues such as civility, charity, and respect for others can guide us here. When they advise engagement, the virtue of humility can assist them through tempering and bolstering.

Start with tempering. Virtues such as civility, charity, and respect sometimes advise engagement with in-the-wrong others. When they do so, the virtue of humility, through limitations-owning, can assist by tempering our uncivil, uncharitable, and disrespectful beliefs, behavior, and emotions, making disengagement less likely. By way of illustration, return to Frederick Douglass. In the decades preceding the Civil War, some abolitionists advocated the secession of the Free States and forming a new country in which slavery was illegal, one dissociated with the remaining slave-holding United States. They rallied under the motto "no union with slaveholders." Douglass $(1855,32-33)$ rejected this position, arguing that it

leads to false doctrines, and mischievous results...It condemns...our Savior, for eating with publicans and sinners... [moreover,] to dissolve the Union, as a means to abolish slavery, is about as wise as it would be to burn up this city, in order to get the thieves out of it.... We hear the motto, 'no union with slaveholders', and I answer it...'No union with slaveholding'. I would unite with anybody to do right; and with nobody to do wrong.

Douglass argued that those in the wrong, even those heinously and ridiculously in the wrong, are not beneath our engagement. We suspect that humility helped him make this argument by tempering his ambitions, beliefs, and emotions. In any case, Douglass did engage with his oppressors, in his context of disparity. Even if humility did not in fact support him in this respect, it would have been apt to do as much.

Douglass has an unlikely ally in Megan Phelps-Roper, who left the cult-like Westboro Baptist Church in 2012, an anti-Semitic and anti-gay hate group comprised almost entirely of the Phelps-Roper family. She credits her departure to others outside the Church who engaged her. In her Ted talk, she encourages such engagement: “My friends on Twitter didn't abandon their beliefs or their principles, only their scorn. They channeled their infinitely justifiable offense and came to me with pointed questions 
tempered with kindness and humor.... They approached me as a human being and that was more transformative than two full decades of outrage" (Phelps-Roper 2017). Here we see the tempering of belief, behavior, and emotion that humility can provide, curtailing unrelenting rage and hatred toward people like Phelps-Roper, helping us to avoid jumping to the conclusion that she is a monster, and enabling suitable engagement. ${ }^{7}$

The virtue of humility not only tempers belief, behavior, and emotion by keeping us from underowning our limitations, but also bolsters those things by keeping us from over-owning limitations. The bolstering, no less than the tempering, can help us engage in-the wrong others in cases where virtues like charity and civility call on us to do as much. This is because over-owning one's limitations, no less than under-owning them, can make one disinclined to engage. People who over-own their limitations might be disinclined to engage in-the-wrong others because they mistakenly fail to be angry or dismayed with those in-the-wrong others or because they mistakenly think they can't make a worthwhile difference and fail to set appropriately ambitious goals. The virtue of humility blocks these kinds of failures to engage because, keeping us from over-owning our limitations, it bolsters our beliefs and emotions.

\section{Answering some worries}

In keeping with the worries from Du Bois and Snow above (page XXX), Robin Dillon argues that "to laud humility for its usefulness to others borders on sinister, given the long history of casting it as a virtue of subordinated peoples-how much easier to dominate those who believe that submissiveness makes them good" $(2015,45)$. Here, Dillon understands humility as a kind of "lowliness, submissiveness, degradation of position or value, abasement" $(2015,45) .^{8}$

Humility, understood like this, is no doubt inappropriate in contexts of disparity. However, the expressions of humility sketched above are not like this. For instance, someone who owns their moral and intellectual limitations, and who thereby makes way for charity to prevent them from unduly vilifying flatearthers and neo-Nazis, does not manifest lowliness, submissiveness, degradation, or abasement. On our theory, lowliness is an excess of the trait of humility and not a manifestation of the virtue; it is a kind of servility, of over-owning one's limitations, and it is often vicious. It causes inappropriate actions and emotions in contexts of disparity. Far from exemplifying the virtue of humility for those in the right in contexts of disparity, lowliness and submissiveness and degradation and abasement are incompatible with the virtue of humility for those people in those cases. Thus we agree with Hannah Gadsby, who in her remarkable standup routine Nanette (2018) says

I built a career out of self-deprecating humor.... And I don't want to do that anymore. Because do you understand what self-deprecation means when it comes from somebody who already exists in the margins? It's not humility, it's humiliation. I put myself down in order to speak, in order to seek permission to speak, and I simply will not do that anymore... If that means that my comedy career is over, then, so be it.

Hear hear. Humility is not humiliation. Though an excess of the trait of humility can bring one to humiliate oneself, the virtue of humility enables informed, forceful, and courageous moral and intellectual action of the sort Gadsby here exemplifies.

Another worry is that humility is inappropriate in contexts of disparity because it involves deference and deferring, e.g., to a flat-earther or a neo-Nazi, is inappropriate; or because it involves low concern for status, which is "implausible with respect to members of oppressed groups" who "must be very concerned...about how others perceive them (especially the powerful)" (Daukas 2019, 381). We agree that deferring to a flat-earther or a neo-Nazi is inappropriate, and that it is appropriate for the oppressed to be concerned with status. On our theory, deferring and low concern for status are 
characteristic manifestations of the virtue of humility in some contexts, e.g., in contexts of privilege. But in contexts of disparity, deferring and low concern for status are characteristic manifestations of the vice of servility instead of the virtue of humility.

Let's unpack this a bit. On our theory, people with the trait of humility characteristically defer to others and even have a low concern for status. Indeed, on our theory, these are also characteristic of the virtue of humility in privileged contexts, contexts in which people do not differ dramatically along some normative dimension like social power or moral status or epistemic credentials, with some in the right and others in the wrong. To illustrate, imagine an academic giving a talk at a department colloquium, and now add that this is not a context of disparity. Relative to this context, audience members with the virtue of humility who lack knowledge about the speaker's topic will be aware of this gap in their knowledge, own it, and so likely defer to the speaker on a range of points. They will also be relatively unconcerned with their professional status, and thus won't grandstand or play games of 'one-up-man-ship' in the Q\&A. Rather, they will ask questions that they don't already know the answers to and they will not pretend expertise on the speaker's topic. If the speaker also has the virtue of humility, they will likely admit when they don't know the answer to a question or have no reply to an objection.

However, on our theory, in contexts of disparity, it is not appropriate to defer to in-the-wrong parties; moreover, in such contexts, concern for status is appropriate for in-the-right parties. Deferring and lack of concern manifest the vice of servility in such contexts. Consider severe cases of oppression in which one needs to be concerned with one's status in order to survive. This is not, of course, a concern for one's professional status (as above); it is a concern for one's status as a person. Now, consider what it would be like to be in this context and to limitations-own in such a way that one comes to have a low concern for one's status as a person-one no longer cares about one's entitlements as a person or about being seen and treated as property. Relative to this context, low concern for status is characteristic of the vice of servility, rather than the virtue of humility. Next, consider someone who limitation-owns in such a way that they come to defer to the neo-Nazi or the flat-earther. Imagine a person who is so focused on their own limitations that they don't trust their own views, or don't trust their ability to figure out what is wrong with the views of the flat-earther or the neo-Nazi, and so they defer. This, too, is characteristic of the vice of servility, rather than the virtue of humility.

\section{Future work}

Many relevant questions remain. Do similar puzzles apply to other virtues such as honesty or courage? Would arguments analogous to ours help resolve those puzzles? On the puzzle of humility and disparity in particular, does the limitations-owning theory do better than other theories of humility might? More generally, how do the numerous theories of humility compare to one another concerning their success in solving this puzzle? Do contexts of epistemic disparity such as those involving flat-earthers connect to the epistemology of disagreement? Are those contexts usefully theorized as featuring extreme non-peer disagreement? Do contexts of disparity involving heinous views and social power connect to liberatory epistemology, for instance to work on epistemic injustice and white ignorance? Do our arguments about contexts of disparity apply equally to interactions with climate-deniers or dogmatic Trump-supporters? Do they tell us anything about humility and political polarization? We have yet to explore these matters. ${ }^{9}$

\section{References}

Aristotle. 1998. Nicomachean Ethics, trans. D. Ross. New York: Oxford University Press.

Baehr, Jason. 2011. The Inquiring Mind. New York: Oxford University Press.

Battaly, Heather. 2015. Virtue. Cambridge: Polity Press.

Battaly, Heather. 2017. "Intellectual Perseverance." Journal of Moral Philosophy 14(6): 669-697. 
Card, Claudia. 1996. The Unnatural Lottery: Character and Moral Luck. Philadelphia: Temple University Press.

Cherry, Myisha. 2017. "The Errors and Limitations of Our 'Anger-Evaluating' Ways." In Cherry and Flanagan (eds) The Moral Psychology of Anger. Rowman and Littlefield, pp. 49-65.

Coplan, Amy. 2010. "Feeling without Thinking: Lessons from the Ancients on Emotion and Virtueacquisition." In ed. H. Battaly, Virtue and Vice, Moral and Epistemic. Malden, MA: Wiley-Blackwell, 133-151.

Daukas, Nancy. 2019. "Feminist Virtue Epistemology." In ed. H. Battaly The Routledge Handbook of Virtue Epistemology. New York: Routledge, 379-391.

Dillon, Robin. 2015. "Humility, Arrogance, and Self-respect in Kant and Hill." In eds. M. Timmons and R. N. Johnson, Reason, Value, and Respect. Oxford: Oxford University Press, 43-69.

Douglass, Frederick. 1885. The Anti-Slavery Movement: A Lecture Before the Rochester Ladies' Anti-Slavery Society. Rochester: Press of Lee, Mann, \& Co. https://babel.hathitrust.org/cgi/pt?id=inu.30000005087683;view=1up;seq=40 $\quad$ (accessed 12/26/2018).

Douglass, Frederick. 1892. The Life and Times of Frederick Douglass. Boston: DeWolfe and Fisk. https://docsouth.unc.edu/neh/dougl92/dougl92.html accessed 12/20/2018).

Du Bois, W.E.B. 1903/1994. The Souls of Black Folk. Mineola, NY: Dover.

Grasswick, Heidi. 2019. "Epistemic Autonomy in a Social World of Knowing" in H. Battaly (ed.) The Routledge Handbook of Virtue Epistemology (Routledge), pp. 196-208.

Helgevold, Abbylynn. 2013. Humility, Oppression, and Human Flourishing: A Critical Appropriation of Aquinas on Humility. Ph.D. Dissertation, University of lowa.

hooks, bell. 1995. Killing Rage. New York: Holt.

Hume, David. 1751/1975. An Enquiry concerning the Principles of Morals. In Hume's Enquiries Concerning Human Understanding and Concerning the Principles of Morals, ed. L. A. Selby-Bigge, 3rd ed. revised by P. H. Nidditch. Oxford: Clarendon Press.

Jones, Karen. 2012. "The Politics of Intellectual Self-trust." Social Epistemology 26(2): 237-251.

King, Martin Luther. 1963. The Strength to Love. New York: Harper and Row.

La Guardia-Lo Bianco, Alycia. 2018. Suffering and Self-Sabotage in Ethical Life. Ph.D. Dissertation, University of Connecticut.

Phelps-Roper,

Meghan.

2017. https://www.ted.com/talks/megan phelps roper i grew up in the westboro baptist church here $s$ why i left (accessed 12/26/2018).

Silvermint, Daniel. 2017. "Rage and Virtuous Resistance." The Journal of Political Philosophy 25(4): 461486.

Snow, Nancy. 2004. "Virtues and the Oppression of African Americans." Public Affairs Quarterly 18(1): 5774.

Tanesini, Alessandra. 2018. "Intellectual Servility and Timidity." Journal of Philosophical Research 43: 2141.

Tessman, Lisa. 2005. Burdened Virtues. Oxford: Oxford University Press.

Watson, Gary. 1984. "Virtues in Excess." Philosophical Studies 46(1): 57-74.

Whitcomb, Dennis and Heather Battaly, Jason Baehr, and Daniel Howard-Snyder. 2017. "Intellectual Humility: Owning our Limitations." Philosophy and Phenomenological Research XCIV(3): 509-539.

${ }^{1}$ Responsibility can also extend to bystanders with privilege.

${ }^{2}$ On courage, see Tessman (2005, 125); on self-respect, see Dillon (2015); on self-trust, see Jones (2012). 
${ }^{3}$ See Cherry (2017) on some of the difficulties involved in trying to do so.

${ }^{4}$ Thanks to June Tangney and Robert Emmons for suggesting these ideas about seeking and accepting assistance. Also, compare Helgevold $(2013,148)$ : “...humility is not simply about restraint; it is about being disposed to hope for the right kinds of excellence (those that are actual possibilities) in the right kinds of ways (i.e., those that reflect an awareness of the influences of others)". La Guardia-Lo Bianco (2018) addresses the relationship between the ill, humility, and seeking assistance.

${ }^{5}$ In a similar vein, Tessman advocates cultivating virtues that involve a "self-reflective understanding (and perhaps acceptance) of the limitations of the moral health of a self under oppression" (2005, 31; cf. 94), virtues that can help one recognize and come to terms with, e.g., limitations in one's capacities to survive or resist. Clearly, humility is one of these virtues.

${ }^{6}$ Grasswick (2019) addresses epistemic autonomy in the context of oppression.

${ }^{7}$ Douglass and Phelps-Roper highlight a key point: we should not conflate humility with openmindedness. Even when it is appropriate to manifest humility in one's interactions with in-the-wrong parties, this need not-and in many cases should not-involve an open-minded consideration of their reprehensible actions, beliefs, or sentiments. Rather, humility clears obstacles to appropriate engagement.

${ }^{8}$ Elsewhere, Dillon says humility involves an awareness of one's moral limitations $(2015,65)$. She argues that, so understood, it can be a virtue, when in the service of self-respect; but if we understand it as lowliness, it is a vice.

${ }^{9}$ For help we thank Alex Arnold, Jamie Aten, Nathan Ballantyne, David Briggs, Ryan Byerly, Michael Byram, Fabiana Cardetti, Charlie Crerar, Kim Cameron, Don Davis, Robert Emmons, Jorge Garcia, Peter Hill, Josh Hook, Frances Howard-Snyder, Peter Howard-Snyder, Rick Hoyle, Hud Hudson, Christian Lee, Tracy Llanera, Michael Lynch, Elizabeth Krumrei Mancuso, Dan McKaughan, Bradley Owens, Michael Pace, Dee Payton, Sara Protasi, Wade Rowatt, Steve Sandage, Paul Shoemaker, Sandra Sirota, June Tangney, Neal Tognazzini, Manuela Wagner, and Ryan Wasserman. Work on this paper was supported by John Templeton Foundation Grant 60622, "Developing Humility In Leadership". 